\title{
Blanchot: La detención de Orfeo
}

Silvio Mattoni

CONICET- Universidad Nacional de Córdoba- Argentina

\begin{abstract}
Resumen
Este trabajo realiza una lectura cerrada de un texto de madurez de Maurice Blanchot, donde el autor plantea la relación de su lectura crítica con sus obras literarias de juventud. A partir de dicho análisis, se establecen conexiones conceptuales y referencias que apuntan a un recorrido más amplio en la escritura teórica del autor. En tal sentido, la recurrencia de ciertas figuras mitológicas, así como de ciertas nociones y nombres de escritores, permite establecer un trayecto no sistemático, pero no por ello menos riguroso que se constituye como la herencia teórica, crítica y filosófica de Blanchot para todo pensamiento actual que aborde los problemas del espacio literario.
\end{abstract}

Palabras clave: estética; teoría literaria; filosofía del arte

\section{Resumo}

Este artigo realiza a leitura atenta de um texto de maturidade de Maurice Blanchot, em que o autor coloca em relação sua leitura crítica com obras literárias de sua juventude. A partir dessa análise, estabelecem-se conexôes conceituais e referências que apontam para um percurso mais extenso na escritura teórica do autor. A este respeito, a recorrência de certas figuras mitológicas, bem como de certas noçóes e nomes de autores, permite estabelecer um trajeto não sistemático, mas não por isso menos rigoroso, que se constitui como a herança teórica, filosófica e crítica de Blanchot para todo pensamento atual endereçado à abordagem dos problemas do espaço literário.

Palavras-chave: Estética; teoria literária; filosofia da arte. 
1. Hay una edición previa, también lejana, en 1953.
En el año 1983, Maurice Blanchot acepta volver a publicar en un libro dos relatos de juventud: "El idilio" de 1936 y "La última palabra" de 1935, bajo el título común de Le ressassement éternel', que un tanto arduamente podría traducirse como El repiqueteo eterno o bien la "recuperación eterna", el "retorno", la "recapitulación", la "insistencia", donde en todo caso el adjetivo de "eterno" se refiere más bien al carácter incesante, reiterativo de un movimiento, antes que al rasgo típico de las ideas platónicas, fijadas desde siempre y sin cambios en un ser atemporal. Ahora bien, esos dos antiguos relatos le inspiran al autor la duda que impone su lejanía. ¿Acaso anticipan algo que se sigue siendo, esencialmente? ¿Anuncian algo en la ficción que el pensamiento todavía no podía ver? Pero más allá de su posibilidad profética, visible sólo cincuenta años después, ¿cuánto valen? ¿Qué dicen de la literatura?

Ya el hecho de que un primer relato se titule "La última palabra”, el término final, el signo de un silencio que se contempla sin poder mirarse en la imagen sustraída de la propia muerte, indicaría que entonces se abría no una ingenua carrera literaria, si puede decirse así, sino la imposibilidad misma de la escritura. La obra, desde el inicio, no podía ser escrita, aun cuando a la última palabra sigan otras, y a pesar de que siempre hubo y habrá nuevas y definitivas, posteriores a las últimas palabras. Lo póstumo se yergue como una pared monumental que la vista del autor no podría tolerar, muro ciego que torna irrealizable toda obra. Pero justamente esa imposibilidad, anunciada en los intentos narrativos de los años 1930, será la idea huidiza de una obra y de su escritura como persecución de tal huída.

Desde ese lugar postrero, posterior, casi póstumo de sí mismo, Blanchot entonces publica o republica sus viejos relatos, pero el libro se llama: Après coup, précédé par Le ressassement éternel. ¿YY qué es ese après coup? Nuevamente se plantea cierta incertidumbre de traducción, ya que se trata de una frase hecha, un giro más bien, que se usa para decir lo que llega a destiempo, o aquello cuyo efecto viene a realizarse después de haber sucedido. Dentro del oficio de traducir dicho giro se plantean algunas opciones, que obedecen a los diversos contextos posibles, pero en un título, que omite incluso el esperable artículo, que no dice "l'après coup", tal como si fuese una categoría, esa denominación de un darse cuenta después o del efecto retardado del síntoma con que un ingenio francés supo leer a Freud, ¿qué podría hacer un probable traductor? Dejarlo tal cual, quizás, ya que no es inusual que muchas expresiones francesas circulen por la cultura mundial y de hecho fueron casi endémicas en el siglo XIX, afrancesado par excellence. O bien intentar el castizo "a destiempo" o el latino "a posteriori”. Pero se escaparía la literalidad del "golpe". Se trata en verdad de un golpe que llega después, incluso de un tiro (como una "tirada de dados") que demora su 
llegada al blanco. De igual modo que la "última palabra" nunca puede ser leída por quien la escribe, tampoco la perpetua recuperación de lo escrito podrá ser terminada nunca. "Après coup" es el epílogo, la reflexión de un autor que ya escribió (¿mucho o poco?, imposible decidirlo) acerca de sus tentativas iniciales de escribir. Sin embargo, ese destiempo, incluso el sesgo profético de los textos, impedirá en realidad que el golpe se dé. El autor no puede leerse, la obra -si existe- no es para él. Tal es la conclusión del epílogo.

Aunque más vale analizar en detalle su movimiento, su acercarse al rescate de la juventud y de una literatura firmada por ella que sin embargo se mantiene a distancia, como si los papeles pudieran pulverizarse al contacto con las manos profanas, profanadas por el tiempo real, mundano, de un yo que ha dejado de ser, que nunca fue el que escribía antaño. El libro, signo de incomunicación y a la vez de contagio entre dos soledades, ¿por qué habría de necesitar dicho posfacio? Blanchot empieza pues su breve mirada retrospectiva, con ese rechazo de todo tercero entre el silencio del libro y el lector desconocido e incognoscible, mirada que de inmediato se enfrenta con una esencial interdicción: "Noli me legere". Tal es la admonición que lo escrito le dirige a su supuesto autor, como la aparición de un fantasma que se sustraería, o se ofendería, o se disolvería si un solo dedo quisiera rozarlo. "No quieras leerme", frase que despide, expulsa al autor de su impropiedad, del libro donde la firma apenas sella esa radical exterioridad de una persona real con respecto al espacio de la obra. Y sin embargo, incluso por la negativa, el viejo libro le dice algo a aquel que supo fracasar o que se hundió en él casi sin saberlo. Porque el escritor, negado en el libro que no lo deja juzgar ni decir nada esencial a su respecto, sueña que existe por haberlo escrito, precisamente. La obra, según Blanchot, le dice: "No subsisto como texto por leer sino por la consumación que lentamente te quitó el ser al escribir"2. O bien: "Nunca sabrás lo que escribiste, aun si no escribiste más que para saberlo". El que escribía de alguna manera se investigaba a sí mismo, buscaba saberse, pero el logro de su acto habrá sido no reconocerse nunca en ese lugar, origen que no puede ser tocado por la cosa originada. Si el escritor lo es por haber escrito, lo escrito no puede ser alcanzado por ese resultado distante, la figura del escritor. "Antes de la obra, obra de arte, obra de escritura, obra de palabra, no hay artista ni escritor ni sujeto hablante, puesto que la producción produce al productor, lo hace nacer o aparecer, poniéndolo

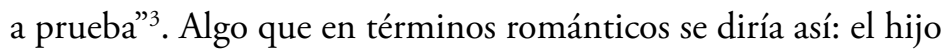
es el padre del hombre. Lo que también significa el abandono del padre. Porque mientras escribe, casi en ese único momento, su acto le prueba algo al agente que lo emprende y le permite ser escritor, pero es apenas un instante, casi sin posibilidad de reflexión, ya que al darse vuelta para admirarse o corregirse la si-
2. BLANCHOT, Maurice.

L'après coup, 1983, p. 85.

Todas las citas de este libro son traducción nuestra.

3. Ibídem, p. 85-86. 
4. Ibídem, p. 86.

5. Ibídem, p. 86. lueta se desvanece, no había nada, fragmentos de lenguaje entre repeticiones y combinaciones, como una red de frases deshilachada sobre la cual hubiese pasado una garra. Deduciéndola de la lógica entre producción y producto, Blanchot puede afirmar esa anticipación de la muerte, la última palabra que sería toda literatura: "Pero si la obra escrita produce y prueba al escritor, una vez hecha no atestigua más que la disolución de este último, su desaparición, su defección y, para decirlo brutalmente, su muerte, por otra parte nunca definitivamente constatada: muerte que no puede dar lugar a una constatación”“ . No sólo sucede que la obra se sustrae en el horizonte de la imposibilidad y que nada parece indicar, para el supuesto autor, su retorno, sino que además la muerte en el libro se torna incomprobable.

La desaparición elocutoria de quien escribe, como decía Mallarmé, no significa necesariamente una muerte, una definición cualquiera; simple paréntesis, interrupción del tiempo y su ilusión en la así llamada conciencia. Entre la imposibilidad de leerse y la imposibilidad de morir, el fantasma del autor deambula por las orillas de las páginas surcadas por su mano, vagamente recordadas en relación con un tiempo borrado. "Antes de la obra, el escritor todavía no existe; después de la obra, ya no existe más", leemos. Y precisamente lo que viene después, a posteriori, après coup, ¿no es el espacio mismo de la crítica, y en este caso: la autocrítica? En lugar de preparar lo que se ha de escribir, la crítica consistirá en el ausentarse de la obra, allí donde el espacio literario, antes abierto en una promesa de posible recuperación, se cierra, se clausura por la súbita profanación de una mirada hacia atrás. Pero el problema del escritor, ausentado en su misma producción, que se vuelve crítico, que se congela en su mirada retrospectiva, sería el porqué de su acto: ¿por qué volver la mirada hacia ese rostro pasado que se disolverá, como es bien sabido, apenas se lo observe? Vuelta de Orfeo, poeta vaciado de su propia intimidad, que mueve todas las cosas pero ya se anuncia como una cabeza parlante sobre un oleaje rítmico y vacío, hacia la belleza que habría anhelado rescatar, lo escrito, la huella sensible de una musa viviente. Pero en cuanto se da vuelta, el sabor se hace amargo primero, y lo vivo que se creyó tener atrás se interrumpe, se convierte en la forma abstracta de toda muerte: la interrupción. Blanchot, que ya selló con el mito de Orfeo, en su obra crítica más cercana al devenir de la literatura sin más, la figura del escritor, puede reiterar la sentencia varias décadas después: “Del 'todavía no' al 'no más', tal sería el recorrido de lo que llamamos el escritor, no sólo su tiempo siempre suspendido, sino aquello que lo hace ser por un devenir de interrupción"5. El riesgo de esta observación sería que lo posible prevalezca sobre cualquier acto, que la interrupción misma prescinda al fin de la obra, puesto que esta última, por más lograda que parezca, también prescindirá del autor y lo condenará a la ridiculez 
del actor que cumple un papel secundario. Pero incluso si la obra se reduce a su extrema pobreza, escritura blanca, frases no extraordinarias, personajes sin espesor, palabras limitadas a su inminencia de últimas, a espaldas del yo así autolimitado, en su devenir inconsciente, se construye la obra no sabida, aun cuando el culpable de ella no quiera de ninguna manera darse vuelta a mirarla. "Sî", insiste Blanchot, "si la obra, en esa operación, por mínima que sea, es destructiva a tal punto que introduce al operador en el equivalente de un suicidio, ¿cómo podrá entonces volverse (ah, el culpable Orfeo) hacia aquello que piensa llevar a la luz, apreciarlo, considerarlo, reconocerse en ello?"6. La injusticia de semejante intención juzgadora, que apreciaría o no, se reconocería o no en lo ya escrito, desplaza el eje de la culpa de escribir: Orfeo sabe que su darse vuelta aniquilará a la figura que lo sigue, pero aun así...

Por lo tanto, ella, la musa que no deja huellas sobre la tierra, el impulso originario e irrecuperable, no le ordena sino que le ruega, en susurros, a sus espaldas: Noli me legere, o sea: "Por favor, no quieras leerme". Es una solicitud de cortesía, pero también una advertencia insólita, una prohibición tenue que desde su pronunciamiento ya ha sido transgredida. ¿Acaso el autor no es justamente, como pensó Mallarmé, el primer lector de lo que sucede, misteriosamente, en el espacio blanco de la página? ¿Acaso la mancha de la escritura, negro sobre blanco, no se reconoció desde el instante en que se esparció, imborrable, como lo ya leído, puntuado, medido, dividido por la mirada que nunca deja de volver atrás? El verso mismo, en el caso de Mallarmé, es un retroceso órfico y sin sentido. A lo cual Blanchot, el joven narrador y el crítico maduro, se intentaba sustraer mediante la forma de la sentencia final, sentencia de muerte y palabra última, narración sin avance, contemplación de lo más alto que se abre infinitamente como inexistencia, pero esa noche definitiva, que no progresa, también se da vuelta para mirar el espacio de sus constelaciones, se vuelve finalmente "teoría".

La teoría sabe que el encanto de la obra, de Eurídice, puede desaparecer en la obstinación, en la machaconería (le ressassement) de su misma contemplación. Pero el poeta no quiere saber eso, al menos en el momento del transporte, en la inspiración. Luego el verso mismo, su retroceso hacia el sonido, se vuelve teórico, excava su sentido hasta convertirse en nada. "Excavando el verso encontré la nada”, decía Mallarmé, con quien el diálogo de Blanchot fue incesante. La ley, o sea la literatura, habrá de disolver con su luz institucional el misterio de la obra. Puesto que Eurídice, sueño del poema, dice Blanchot: "es tentadora para el encantador cuyo deseo es asegurarse de que hay en verdad alguien bello que lo sigue, antes que un simulacro fútil o una nada envuelta en palabras vanas"7. Y sin embargo, lo cierto es que a posteriori una cosa escrita o dicha es más bien un simulacro y
6. Ibídem, p. 88.

7. Ibídem, p. 89. 
8. Ibídem, p. 90.

9. Ibídem, p. 91. quizás nada, vacío alrededor del cual giran palabras. Aunque el deseo de una obra no pueda seguir sin el sueño de la presencia, sin "alguien".

En ocasiones, la transgresión del mandato que lo escrito impone a su autor (noli me legere) se repite, se obstina; es la lectura en voz alta. Leerle entonces el poema o el relato a un público que no interesa, que no es alguien, redobla a fin de cuentas la transgresión mental originaria, que ha ocurrido apenas pasa el instante de escribir, o incluso en el mismo lapso en que la ocurrencia de versos y frases encuentra su cierre y su corrección. La lectura en voz alta sería la impostación de una voz que nunca se tuvo, dándole a alguien que no está presente el don de una presencia ya desaparecida. Sin embargo, el autor-actor, poniéndose en el doble escenario de lo que no puede juzgar, pero que ahora debe interpretar, acaso logre conmover otra cosa en sí mismo, como un Hamlet que pusiera en escena su propio crimen olvidado para traerlo de nuevo al orden del lenguaje.

En ese redoblamiento, en la duplicación irónica de la apariencia que se muestra como apariencia, se revelaría entonces una verdad sin comentarios, más allá de toda literatura. Pero, ¿de qué se trata? Glosarla o prologarla sería darse vuelta hacia su inminencia, disolviéndola. Verdad de la escritura que siempre le pertenece a otro. $\mathrm{Y}$ en el caso de Blanchot ese otro habrá sido Bataille, el amigo que escribió en aquellos años de juventud la nouvelle Madame Edwarda, en cuyo texto lo único, el trastorno que introduce la emoción y el mutismo, podían bastar para justificar la vida. Sin embargo, los años hacen luego del texto un objeto, se despliega su núcleo incandescente, se lo inscribe en la literatura. El mismo Bataille quisiera escribir una continuación: "No pude sino contestarle de inmediato, y como si me hubieran dado un golpe [coup]: 'Es imposible. Por favor, no lo toque."." Y precisamente ahora, así como el amigo no pudo evitar ańadir un prefacio al libro clandestino, para ponerle al fin su nombre propio, Blanchot le da el golpe de un posfacio a los relatos que no puede juzgar. Tarea vana o necesaria para la crítica, para la existencia siquiera imaginaria de un diálogo inconcluso que le da cierta supervivencia a la lectura de una obra, pero igualmente sin prólogos ni epílogos el desastre era inexorable: la escritura, la noche intensa y sin expectativas, se habrá de transformar en cosa escrita, un objeto. Blanchot recuerda ese deslumbramiento que sintió ante la inspiración hallada por su amigo: "Queda la desnudez de la palabra 'escribir', idéntica a la exhibición febril de aquella que fue una noche, y en adelante para siempre, 'Madame Edwarda." ". Se recordará: la prostituta ebria y sin embargo señorial abre sus piernas y señala su sexo diciendo que es Dios. La desnudez de escribir no tiene contenido. Se trata de la última palabra dirigida por el deseo al fantasma de su propia imposibilidad. Se trata de un nombre que pueda ser todo para todos, y que 
sea el de nadie, y a la vez el más propio, adherido a la mortalidad del cuerpo que escribe.

Llegamos pues a la última palabra, que fue el principio de la repetición interminable. Porque después de todo, en el golpe que reitera otro golpe, en la lectura retardataria o postrera, lo escrito dice algo, anuncia, promete. No es sólo la felicidad perdida de haber escrito, sino que contiene algo que fue verdadero para alguien. Allí tal vez, y no en el fantasma de un lector ni mucho menos en la masa de varios otros, esté renovada la presencia. “Quién fui?”, decía Michaux, poeta al que Blanchot le dedicara un admirable libro. Y esa es una pregunta crucial, situada al comienzo, a pesar de su verbo en pasado, del insensato camino de la inspiración. "No lo sé", contesta Blanchot. Aunque saber que no se podrá leer sea de pronto la renovación del misterio en la noche iniciática. Escribe: "la convocación abrupta del lenguaje, la resolución insólita de privarlo de sostén, la consigna (más lenguaje coercitivo o afirmativo, es decir, más lenguaje -pero no: siempre una palabra para decirlo y no decirlo), la renuncia a ser Amo y Juez -renuncia vana a su vez-" ${ }^{10}$. Luego, así despojado de todo lo que no sea palabra, abriendo la puerta que comunica con los muertos y los no nacidos, se asiste a la ruina final, cuando hasta las palabras se sustraen, hasta la consigna de no expresar se da vuelta y congela la mirada. ¿Qué queda? Un cuento: "el narrador que ha conservado el privilegio del ego y la muchacha sencilla y espléndida, que probablemente lo sepa todo con el saber más humilde". Eurídice lo sabía, pero no fue un sueño, una nube, estaba siguiendo el ritmo y la escalera ascendente de las palabras mientras se escribían. Y ante el relato de su huella leve, vuelve a alzarse la conmoción de un yo, que asiste a su vaciamiento y a su conversión en cuerpo. Se le revela que la muerte no cabe en las palabras, pero que no es lo único real, sino que también está y estará la amistad, también el deseo, también el amor por los libros que todavía conversan hasta el infinito.

En la misma interrupción de lo que no se pudo decir en otro tiempo se anuncia lo que todavía hace falta decir, y sobre todo se oye una voz. Antes de la retrospección fatal, antes del desencanto, a espaldas de quien escribe, alguien, la belleza por así decir, habla. Eurídice dice algo antes de volver a la sombra. Y con esa palabra última y sin embargo reiterable se podrá seguir conversando, quizás. Acaso sea: "el hay que trae la nada y la aniquilación para que ésta no escape de su proceso interminable cuyo término es repetición (ressassement) y eternidad" ${ }^{11}$. Resulta enigmático en este punto, en esta instancia, que la repetición, que pareciera una acción productora de deterioro, algo que desgasta la materia, un volver a pasar y repasar que elimina de a poco, purificándolo, el polvo a disposición, se enlace con la eternidad. ¿Por qué el relato ilegible, precario, sería eterno? Es como si la voz extraña, la voz amable que yace en el fondo de lo
10. Ibídem, p. 93. Subrayado del autor.

11. Ibídem, p. 94. Subrayado del autor. 
12. Ibídem, p. 98. olvidado, dijera en el instante de su eclipse algo así: la palabra no puede ser borrada.

La paradoja puede resultar acaso incomprensible entre una cosa escrita, que no quiere ser leída, que levanta una prohibición, y una palabra dicha que no puede ser borrada, aun en el olvido y en su carácter de hecho pasado. Y sin embargo, ¿no está el esplendor de lo que pasó y marcó las palabras en el relato, en lo que se dejó escrito, como la impresión sin comentarios de Madame Edwarda para la vida de un lector juvenil que todavía vuelve a leer allí su propio asombro originario? La literatura, dirá Blanchot a propósito del romanticismo de Jena, quiere ser literatura, la declaración de su poder y de su libertad, pero sólo a condición de que la literatura sea todo. Après coup, más tarde, agrega:

A partir de allí, sería posible que toda narración, e incluso toda poesía, hayan perdido el asidero sobre el cual se elevara un lenguaje distinto, por la extinción de la felicidad de hablar que aguarda en el más mediocre silencio. El olvido sin dudas realiza su obra y permite que todavía se sigan haciendo obras. Pero a ese olvido, olvido de un acontecimiento donde se ha hundido toda posibilidad, le responde una memoria desfalleciente y sin recuerdos que asedia en vano lo inmemorial. ${ }^{12}$

Es como si el relato, e incluso el poema, estuvieran destinados a fracasar antes de toda retrospección. Ya en el momento en que Orfeo decide abrir las puertas de su descenso con la potencia rítmica que lo anima, en el hacerse palabras de su compás, ha sentenciado a Eurídice: está mirando la obra a través del deseo de hacerla, ya se olvidó de su objeto amado cuando quedó preso en la fascinación de sus palabras. Y lo que se asedia en vano, la designación deslumbrante de lo inmemorial, aquello que yace en el fondo de lo olvidado para cada ser hablante, por el hecho mismo de hablar, de haber empezado a hablar, es la idea de literatura antes de que fuera posible como tal. La mitología, o sea Orfeo, también románticamente, habrá sido la huella inconsciente, el registro no voluntario, de la idea de literatura que un mundo sin dioses ni musas tuvo que sacar, casi forzosamente, a la luz de los libros. No obstante, aun en la muerte sin frases que sucederá a la luz desértica de las cosas vacías, libros como cosas mudas en el mundo de las cosas, queda la decisión de reflexionar, de volver a pensar en lo que fue, el recuerdo de aquella que una vez siguió los pasos de quien escribe, tal vez sin un final y hasta el final.

"Una voz viene de la otra orilla", escribe Blanchot citando a un amigo filósofo. ¿Habrá sido la voz de ella, literatura o poesía, que al final llamaba desde el porvenir, desde la curiosidad por lo todavía no escrito? Sería como si la última palabra del relato primero se convirtiera con la madurez en la nueva promesa de 
palabras iniciales, a destiempo, pero de una vez por todas acaecidas. El golpe, después, es la recuperación de su impacto en otro lugar, es el entusiasmo y la inspiración aunque sea en la forma reflexiva, en el despliegue orquestado de una voz crítica.

En el orden de la ficción, o en el desastre de su vaciamiento, en su sueño sin referencias, la palabra definitiva corresponde a la voz de una mujer que quiere que le lean: "Ella se desvistió y con el cuerpo cubierto por un largo camisón negro fue a agarrar el libro del que arrancó varias hojas. '¿Sabe leer?', preguntó en voz baja. Me alcanzó unas páginas; nos acostamos uno junto al otro, cada cual tapado por una frazada" ${ }^{13}$. Luego el narrador lee lo siguiente:

Hubo un tiempo en que el lenguaje dejó de unir las palabras entre sí de acuerdo a relaciones simples y se volvió un instrumento tan delicado que se le prohibió su uso a la mayoría. Pero los hombres que naturalmente carecían de sabiduría, inquietos, ansiosos de estar unidos por lazos prohibidos, se burlaron de esa interdicción. Ante semejante locura, las personas razonables decidieron no hablar más. Aunque a éstas nada les estaba prohibido y sabían expresarse, en adelante guardaron silencio. Parecía que sólo hubiesen aprendido las palabras para ignorarlas mejor y, asociándolas con lo más secreto que existe, las desviaron de su curso natural. ${ }^{14}$

No obstante, se diría que el silencio de los sabios en la leyenda ha sido un error, comprobado por la presencia de la oyente, su cuerpo recostado. Su voz insiste más adelante: "hay que seguir leyendo", dice. Finalmente, la torre del lenguaje, el espacio que habitan incluso cuando callan, se derrumba. No quedarán tal vez rastros de las palabras, prohibidas o silenciadas, que unieron al narrador y a su compañera de lecturas. Pero una palabra última insiste y persiste, como la cabeza de Orfeo después de que las fuerzas del tiempo natural dividieron su cuerpo en partes, su poema en versos y en temas, que sigue pronunciando la obra inconclusa o inacabable sobre las olas de un río, flotando.

De igual modo, el gran crítico que ha sido Blanchot escucha aún el sonido, casi el impulso de su escritura pasada; pero entre "La última palabra" y la vuelta de 1983 se abrió la posibilidad de seguir leyendo, de escribir sobre lo inaccesible de una obra, de darle sentido al abandono de las ficciones. Estuvo Orfeo en El espacio literario en 1955, en cuyo avance se atiende más al impulso musical que a su mirada disolutoria. La noche de escribir, su intensidad y su olvido, valen entonces más que la lucidez posterior, que al fin parecería terminar borrando sus huellas. Lo que en la noche de escribir había sido deseo, ritmo, movilidad, en la vuelta atrás de la lectura diurna se convierte en verdad, prosa, crítica. No obstante, Orfeo -o su poema- no po-
13. Ibídem, p. 59.

14. Ibídem, p. 59-60. 
15. Ídem. La conversación infinita, 2008, p. 453-454. dría existir como obra, como idea y mito, sino por la prosa que lo alumbra en su noche, su vuelta atrás; justamente versus quiere decir "dar vuelta hacia atrás" y únicamente la prosa (de pro-versus) le señalará su avance hacia adelante. El ritmo de la escritura retrocede sobre sus pasos sonoros, mientras que el sentido se precipita hacia las conclusiones, se impacienta y aclara. Como decían también los románticos: "La idea de la poesía es la prosa". Entendiendo por "idea" el despliegue trascendental del núcleo crítico de cada poema, la convergencia de la crítica poética con la obra y sus límites. Por lo cual Eurídice, o cualquier relato que pueda ser criticable en este sentido último, de universalidad al menos hipotética, se abre a todas las alegorías: lo escrito, el deseo de escribir, el objeto deseado al escribir, la voz que dicta la escritura, lo involuntario o lo inconsciente que surgen al paso, pero también la voluntad y la conciencia que guían en el camino. Y al final de tantas figuras, Eurídice será sobre todo el poema inexistente ya que, como sabían desde el origen los mitólogos antiguos, no podemos leer la obra de Orfeo, salvo como guía de misterios que no dicen nada sobre el origen y el sentido de la poesía terrenal, mundana.

Ese misterio órfico reapareció, al menos como fantasma, en diversas épocas. Y una en particular tiene relación con la idea de literatura de Blanchot, el ya citado romanticismo de Jena. Entonces lo inacabado o lo fragmentado, lo despedazado y lo proyectado se elevaron al absoluto, pero quizás sin atributos, sin nombres, sin rostros. Blanchot lo comentó así en La conversación infinita en 1969:

el poder, para la obra, de ser y ya no de representar, de serlo todo, pero sin contenidos o con contenidos casi indiferentes y así de afirmar juntos lo absoluto y lo fragmentario, la totalidad, pero dentro de una forma que, al adoptar todas las formas, es decir, no adoptando al final ninguna, no realiza el todo, sino que lo significa suspendiéndolo, y hasta rompiéndolo. ${ }^{15}$

De allí el riesgo romántico: que la totalidad señalada al infinito por el fragmento o la ruina sea una mera hipérbole del "yo". Pero, ¿acaso de Orfeo no queda otra cosa que esa cabeza parlante sobre el oleaje de su despedazamiento? ¿Acaso no se anuló ya la obra en su origen, en su manía originaria? A estas preguntas, los románticos, y Blanchot con ellos, respondieron mediante diversos modos de la crítica y su operación básica, la reflexión. Modos que se declinan bajo los nombres de ironía, formación o aprendizaje y sobriedad. De alguna manera, la lectura postrera le otorga una consistencia mayor a lo escrito y devuelve cada fragmento a la conversación, cual monólogo de un diálogo inacabable que deberá ser la literatura. 
Pero en contra del ideal inasequible que quisiera así profetizar la prosa de la biografía en la conciliación futura de obra y vida, Blanchot propone una escritura del fragmento sin más, en la pura destrucción de cualquier todo. Escribe entonces: "una forma nueva de cumplimiento que movilice el todo interrumpiéndolo y mediante los diversos modos de la interrupción" ${ }^{16}$. Y la interrupción habrá de ser o tendrá que asumir la figura de la muerte, la ajena y la imposible que afectará al que escribe: Eurídice y Orfeo. Se escribe para no morir, tal vez, pero también se escribe para hacer posible la representación de la muerte, que sólo esbozará una idea de obra en el instante de su cumplimiento, es decir, en el momento de inexistencia del escritor que hace existir a un autor. En lucha contra ese monumento póstumo, contra la firma inevitable y el límite inexorable de la vida, Blanchot aspira a dejar huellas de la interrupción pura, al mismo tiempo que sustrae su imagen de todo libro. Se trata pues de instaurar la discontinuidad o la diferencia, el diferir de lo que se está escribiendo y que no tiene final, en el espacio de la forma, en la noche de la inspiración pero también en el día de la sobriedad, en la narración y en la lectura que regresa.

La mirada retrospectiva procura volver de la noche de la escritura con algo tangible. Sin embargo, lo que se trae nunca coincide con el impulso originario. No era la belleza de Eurídice lo que debía devolverse a la luz del día, sino su punto indescriptible, aquello que la puso en el instante detenido del deseo. En medio del camino, Blanchot anotó en El espacio literario: "Eurídice es el extremo que el arte puede alcanzar, bajo un nombre que la disimula y bajo un velo que la cubre, es el punto profundamente oscuro hacia el cual parecen tender el arte, el deseo, la muerte, la noche" ${ }^{17}$. No obstante, la obra no puede ser ese simple punto de inaccesibilidad. La forma, la figura, el rostro que se recuerda y que se anhela, las promesas detrás del velo, inclusive la voz que se oye, el paso que se percibe detrás del yo que escribe, todo aspira a adquirir la consistencia de lo sensible y la persistencia de lo decible. Pero Orfeo, dirá Blanchot, se olvida de esa huella que debería cuidar, quiere solamente el punto ciego, lo informe que no se materializa. Mientras siga el punto ciego, el poema continúa, el ritmo sube. Apenas sospeche que lo traído no coincide con lo recordado, apenas se entregue a la voluntad de saber, la obra se arruina junto con el corte de su ritmo. Toda obra hecha es la ruina de su deseo. En otras palabras: nunca se deja de escribir.

Es inevitable que Orfeo no respete la ley que le prohíbe 'volverse', porque la violó desde sus primeros pasos hacia las sombras. Esto nos hace presentir que en realidad Orfeo no dejó de estar orientado hacia Eurídice: la vio invisible, la tocó intacta, en su ausencia de sombra, en esa presencia
16. Ibídem, p. 460.

17. Ídem. El espacio literario, 1969, p. 161. 
18. Ibídem, p. 162.

19. Ibídem, p. 165. velada que no disimulaba su ausencia, que era presencia de su ausencia infinita. ${ }^{18}$

Ya en el descenso, en la intención de acudir al reino de lo ausente para buscar la ilusión sensible de alguien presente -cuerpo, mirada y voz-, el que escribe se dio vuelta, se miró buscándose, y empezó a desaparecer en lo escrito. ¿Qué queda entonces de ese acto insensato de escribir? ¿Un sentido más puro, un ritmo que no se rinde a la comunicación, la "medida órfica"? Tal vez sólo la vitalidad de una impaciencia, una despreocupación por lo que se está haciendo. Es como si Orfeo se hubiese dado vuelta sin querer, por descuido, distraídamente. Tras un pequeño ripio, en la cesura del verso, en la prosecución de la frase, se da vuelta para comprobar que ella, la que inspira el trayecto, no se haya tropezado, no se haya golpeado. La mera caballerosidad, la cortesía del poeta condena a su dama, así como siglos después la señora de la mente casi no podrá retener nada del nombre, la risa, el color de una muchacha. Pero aun así, en el mismo descuido del paso, en el final del poema, en el olvido de toda obra, se guarda un rastro real, un deseo que insiste, una mortalidad en trance de arribar a la suspensión de su sentencia, o sea a la vida. La despreocupación traiciona la obra, sacrifica la continuidad del poema, rompe con el pasado, sólo para seguir mirando a quien inspira, a quien impulsa. Pero el objeto, que se ha mostrado unido al deseo del poema, se desvanece sin lo escrito. Se vuelve entonces a leer, se elimina lo que sobra, se llega hasta la aniquilación de todo resto; empieza la crítica. No habría obra, su despreocupación y su inocencia, sin el momento culpable que la define, la lee contra su propia ley íntima de misterio o de secreto.

Unos juguetes, un trompo, un muñeco, un espejo, cosas que se "revelaban" en los misterios y que no querían decir nada. Señalamientos que remitirían más bien a la infancia olvidada, al aprendizaje de las palabras, al deseo que no sabe decir su nombre. El día, como el levantamiento del velo, interrumpe la ilusión de una vida continua, cancela hasta el recuerdo de la belleza deseada; entonces los rastros del trayecto, palabras dadas, se transforman en saber. ¿Qué se sabe de lo escrito, si no su desatadura, su momento distante de libertad más allá de la voluntad de obra? Un tanto misteriosamente también, Blanchot contestó:

La mirada de Orfeo es así el momento extremo de la libertad, momento en que se vuelve libre de sí mismo y, acontecimiento más importante, que libera a la obra de su preocupación, libera lo sagrado contenido en la obra, da lo sagrado a sí mismo, a la libertad de su esencia, a su esencia que es libertad (la inspiración es por esto el don por excelencia) ${ }^{19}$.

Paradójicamente tal vez, la marca de esa libertad, que no tiene lugar en el mundo material donde todo está condicionado, 
ni en el cuerpo sobredeterminado de un sujeto, se encuentra en la firma. El nombre del autor viene a ponerle un signo a la interrupción de la escritura, arabesco del punto final. Como señal de una autoridad que le permitiría salir del texto y apropiárselo, la firma es un sinsentido, pero en verdad apunta a lo que no puede decirse, al origen de la escritura, al punto ciego de una mirada y a lo perdido. La firma señala pues la libertad, que es apenas la posibilidad de interrumpir, lo que está entre un fragmento y otro. Signo vacío, heredado antes de toda palabra, la firma sin embargo enlaza con su red de hierro, social y coactiva, el cuerpo de quien escribió su deseo de obra juvenil con ese otro que lee restos escritos en el après coup que le impedirá juzgarse. No obstante, quien firma escribe, sigue escribiendo después. ¿Acaso alguna vez empezó a escribir? ¿Acaso alguna vez se diferenció de su propio nombre? Lo que se escribió en todo caso fue un deseo, que en cierto modo pudo quebrantar el destino del nombre, su carga, su culpa, para darle otro, el de la despreocupación y el de un tiempo desperdigado en fragmentos. Lo que se escribió estaba antes de escribir pero no hubiera sido sin la palabra dada, sin la consagración de una vida a las palabras.

Blanchot: "Para escribir ya es necesario escribir. En esta contradicción se sitúan la esencia de la escritura, la dificultad de la experiencia y el salto de la inspiración" ${ }^{20}$. Se sigue escribiendo, pero lo contradictorio es que esa experiencia nunca se tiene, nunca se aprende, se da por raptos, por momentos. La libertad esencial de la escritura reside en otra voz que le habla al cuerpo y a su olvido en quien escribe. Antiguamente, como ya mencioné, se llamó "musa", pero también pudo llamarse "carencia" o "falta", "deseo", y en un origen irreal, casi religioso, se llamó Eurídice, la ausente.

En esa vocación, atención a la voz, el escritor se va convirtiendo en "algo que no existe", según la frase de Kafka que Blanchot pone al final del ensayo "La última palabra", recogido en La amistad en $1971^{21}$. A ese ausentarse, de textos póstumos y de conversión de todo lo escrito en póstumo, a ese descenso definitivo hacia el après coup y lo suranné de una vida que se transforma en huella, le sigue sin embargo otra palabra, y habrá más, ya que nunca llega la "completamente última". La "última" sería una promesa de vida, que viene después de la penúltima muerta, después de la tónica, en el alargamiento incluso de la sílaba pretónica, pero que coincide con el blanco final de la página. Áfona, la palabra completamente última debe enfrentarse con el infierno de la literatura, su proliferación inconsecuente. Así lo describe Blanchot, precisamente al final de otro ensayo sobre ese deseo de escribir que lleva el nombre de Kafka:

¿Por fin podía, liberado, escribir, es decir, morir? Por fin. Pero la eternidad comenzaba ya: el infierno póstumo, la
20. Ibídem, p. 166.

21. En su momento, un inexplicable capricho editorial publicó el libro traducido con el título de otro ensayo: La risa de los dioses. 
22. BLANCHOT, Maurice. La risa de los dioses, 1976, p. 255.

23. Ibídem, p. 256.

24. Ibídem, p. 258. gloria sarcástica, la exégesis admirativa y pretenciosa, la gran encerrona de la cultura y, aquí incluso, una vez más, esa última palabra que no se propone más que para simular y disimular la espera de lo absolutamente último. ${ }^{22}$

Un velo entonces, de nuevo puesto sobre los juguetes del goce inicial, pero ahora la disimulación se ha vuelto, por así decir, honesta, puesto que se sabe sin conciencia que lo último no cabe en las palabras y hacia ese "punto" todas las palabras apuntan. No obstante, el que se eclipsa espera, el que espera escuchó y obedeció, y todavía se diría que le habla a alguien sobre alguien. Sin la amistad, otra musa, más claramente platónica, no hubiese existido la palabra y su destino. ¿A quién, si no, decirle que queme todos los textos?

Habrá, hubo, se tiene la esperanza de que haya ese otro para quien el noli me legere sea una puerta a la transgresión, una posible cura de la prohibición. De ahí el nombre del libro que acabo de citar, donde Georges Bataille es recordado, subrayado y extrańado. En la amistad, la interrupción que se hubiese creído definitiva, completamente última, se termina convirtiendo en intervalo, espaciamiento de una conversación inconclusa. "Todo lo que decimos no tiende sino a ocultar la única afirmación: que todo debe desaparecer y que no podemos permanecer fieles más que velando por ese movimiento que desaparece, al que algo en nosotros, algo que rechaza todo recuerdo, pertenece desde ahora." ${ }^{23}$. El movimiento de la sustracción y el instante en que desaparece un interlocutor verdadero se sitúan todavía en el intervalo, entre dos monólogos o entre dos silencios. Se trata de "el puro intervalo que, de mí a ese otro que es un amigo, mide todo lo que hay entre nosotros, la interrupción de ser que no me autoriza nunca a disponer de él, ni de mi saber sobre él (aunque fuera para elogiarlo) y que, lejos de impedir toda comunicación, nos relaciona mutuamente en la diferencia y a veces el silencio de la palabra" 24 . En ese intervalo entonces lo que se ausenta sigue vivo.

¿Qué voces más vivas en la cabeza del que lee, sino las de esos escritores amados, muertos, que hacen nacer cada vez el deseo de escribir? Pero no se trata sólo de la obra, ni siquiera existiría en ningún lugar algo llamado "obra", sino de un espaciamiento interior. Allí, lo que se da vuelta puede hacer que nazca lo visible y no sólo destruirlo. En la sombra, con las sombras, se continúa la conversación, el diálogo que somos, esa distancia que sólo hace perceptible la pura felicidad y que sin palabras a veces se ha imaginado. Para que finalmente el orfismo se cambie por la música de Dionisos y la rescatada, feliz Ariadna, tire de un hilo que no pueda romperse. Todo desaparece, como Eurídice, pero también, antes del golpe, en el intervalo, todo brilla en un cielo de apariencia inmutable, como la constelación que trazó 
de una vez y para siempre la corona de Ariadna divinizada. Así, la conversación con Blanchot, sus ideas y su estilo, su riesgo y su alegría, prosigue su camino serpenteante en nosotros. 


\section{Referencias}

BLANCHOT, Maurice. Après coup, précédé par Le ressassement éternel. París: Minuit, 1983.

.El espacio literario. Buenos Aires: Paidós, 1969.

. La conversación infinita. Madrid: Arena Libros, 2008.

. La risa de los dioses. Madrid: Taurus, 1976. 